\title{
Features of Cervical Hip Fracture Treatment Caused By Osteoporosis
}

\author{
Afa Bayramova* \\ Department of Gynaecology, Yaroslavl State Medical University, Russia
}

Submission: January 01, 2017; Published: January 24, 2018

*Corresponding author: Afa Bayramova, Department of Gynaecology, Yaroslavl State Medical University, Yaroslavl Regional Perinatal Center, Yaroslavl, Russia, Tel: +79099555044; Email: yourdoctor.md@gmail.com

\begin{abstract}
Fractures that occur against the background of osteoporosis represent a global medical and social problem. In elderly people, $90 \%$ of hip fractures, as international studies have shown, occur against the background of osteoporosis. According to WHO, it is the fractures of the proximal femur that put osteoporosis on the 4 th place among all causes of disability and mortality.

Keywords: Orthopedic; Osteoporosis
\end{abstract}

\section{Introduction}

The increase in the number of patients with osteoporosis is due not only to aging of the population, but also to the rejuvenation of the disease. There is a clear tendency to an increase in the frequency of fractures against the background of osteoporosis in the age group of 40-60 years [1]. At this age in US women, fractures against osteoporosis became the most common pathology. The risk of fractures of this localization reaches $15 \%$, which is close to the incidence of breast, endometrial and ovarian cancer, combined [2].

In a prospective study conducted in the United States and covering the period from 1928 to 1992, there was a 5-fold increase in the number of fractures of the proximal femur per 100,000 populations [3]. A similar trend is taking place in European countries, which is confirmed by the results of epidemiological studies conducted in the population over 50 . According to forecasts, further increase in the frequency of fractures of this localization is expected. In Finland, for example, by 2010 the increase should be $38 \%$ [4].

Taking into account prospective studies, such growth should be expected. Despite the prevailing opinion about the prevalence of osteoporosis among women, epidemiological studies of fractures of the proximal femur on its background suggest that this is not always the case [5]. So fractures of the proximal femur only in the age group of 50-70 years were more frequent in women, at the age of 75-80 years were equally common in both men and women. The prevalence of men with fractures in the age group over 80 years (1.4 times more often than in women) is explained by the increase in the significance of each fracture in men due to the fact that they are three times less at this age than women [6].

Fractures of the proximal femur are considered the most costly, because, among other things, require hospitalization. According to various authors, patients with these fractures occupy up to $68 \%$ of the beds of orthopedic and traumatological institutions [6]. Analysis of morbidity showed that 25003000 patients with fractures of the femoral neck were treated annually in traumatological hospitals with 2,500 beds [7]. The average length of stay in the hospital was 30-35 days. In Europe and the countries of North America, the cost of treatment and rehabilitation of a patient with a fracture of the neck of the femur ranges from 28 to 40 thousand dollars. Only $1 / 4$ of the observed fractures of the proximal femur end with complete recovery with a good functional outcome [8].

Fractures of the neck of the hip are one of the leading causes of disability. In addition, every fourth patient dies in the first 6 months after the fracture, while in the hospital the death rate is $3 \%$ for women and $8 \%$ for men [9]. In Europe, the mortality rate for fractures of the femoral neck, as shown by epidemiological studies, varies from region to region from $19.7 \%$ to $55 \%$. With conservative treatment, requiring a prolonged bed rest, the mortality rate is $40 \%$. More effective tactics for fractures of the proximal femur are, according to general opinion, surgical treatment [10]. In elderly people with co morbidities, surgical intervention has a high degree of risk. This circumstance requires interventions in the early period after trauma, before the development of somatic complications. An emergency 
operation and early activation of patients reduce the risk and severity of complications, and are a factor in the mechanical stimulation of osteogenesis.

Meanwhile, the results of operative treatment of fractures against the background of osteoporosis cannot be considered satisfactory. As a retrospective analysis of treatment of 360 patients with femoral neck fractures showed, in only $15 \%$ of patients the ability to move without additional support is restored, in $22 \%$ of cases the result of treatment is unsatisfactory. The frequency of false joints, according to some data, reaches $30 \%$ [3]. In many respects this is due to the fact that due to the expressed rarefaction of the bone trabeculae at the time of surgery, it is not possible to achieve primary stability. Adaptive bone tissue rearrangement around the implant in the early postoperative period further increases the rarefaction of bone structures $[11,12]$.

\section{The solution of the problem of treatment of femoral neck fractures against the background of osteoporosis consists of:}

1. In the development of adequate methods of surgical treatment and the use of fixatives, minimally damaging bone tissue [13].

2. Pharmacological correction of disturbed remodeling aimed at increasing bone mass and improving its quality. The least traumatic, as studies have shown, is osteosynthesis with a bundle of spokes. With the introduction of primary tensioned spokes into fragments, bone bolls along the perimeter of the fixer are destroyed less than when forming a channel for large structures, which in combination with a constant tension between the spokes creates optimal conditions for healing [13].

Indications for polytensophascic osteosynthesis as the first stage of combined treatment are basal, transcervical and sub capital fractures of the femur with an angle between the fracture plane and the horizontal plane of the pelvis to 50 degrees and a small displacement of the fragments. According to Powel's classification-fractures of 1-2 types. The presence of a type III fracture according to this classification is a contraindication for the use of polytensophascic osteosynthesis by a V-shaped needle $[13,14]$. With significant displacement of fragments preference is given to end prosthetics. The use of $1.8 \mathrm{~mm}$ diameter spokes widely used in trauma hospitals significantly reduces the cost of treatment. Walking with a dosed load after surgery is usually allowed already for 2-3 days. Early load in polytensophascic osteosynthesis in patients with osteoporosis has a positive effect on impaired bone remodeling.

The second stage of combined treatment is the appointment of pharmaceuticals that affect the remodeling of bone tissue. The ultimate goal of pharmacological correction is to increase the mass of bone tissue (assessed by its mineral density, BMD) and improve the quality of bone tissue $[6,15,16]$. At the time of injury, as well as during the implantation of metal structures, regardless of the nature of the disturbance of bone tissue metabolism ("high turnover" or "low turnover" osteoporosis), the intensity of bone resorption (stress remodeling) increases both between fragments and in the area of the needle transmission, which accelerates destruction of adjacent bone bunches and may lead to instability of fixation of fragments. In order to prevent this possible complication, it is advisable to prescribe antiresorptive pharmaceuticals [9].

Previously, a placebo-controlled study of the efficacy of the injectable administration of calcitonin, which has a central analgesic effect, in combination with calcium preparations or only calcium in fractures of the radius in a typical place in postmenopausal women $[8,17]$. The metacarpal index was used as an evaluation criterion. Patients receiving calcitonin and calcium showed an increase in the metacarpal index and the ratio of the cortical bone area to the total bone area (CA/TA), and a decrease in the level of tartrate-resistant acid phosphatase. In the group of patients who received only calcium, no changes were detected [18].

In the placebo group, there was a decrease in the metacarpal index and CA/TA. A double-blind, placebo-controlled study of the intranasal use of calcitonin in hip fractures in 2002 on a large (260) number of patients showed a positive effect of the drug on the number of adhesions achieved [16]. According to available data, fractures of the proximal femur are more often detected in individuals with low concentrations of active metabolites of vitamin D3 in the blood [11,12]. Disturbances in the calcium homeostasis system and data on low concentrations in the blood of their active metabolites of vitamin D3 were the basis for prescribing active metabolites of vitamin D3 and calcium preparations in a complex of pharmacological correction. Active metabolites of vitamin D3, as shown in bone cell culture, affect the proliferation of osteoblast precursors, activate bone formation processes and improve the mineralization of newly formed bone tissue (according to histomorphometric data), improve the absorption of calcium in the intestine [14].

In addition, active metabolites of vitamin D3 not only increase bone mass and BMD, but also positively affect the quality of bone tissue, including cortical, which determines the strength properties of this part of the skeleton [11]. In an open placebo-controlled study, it was shown that with fractures of the femoral neck, the need for intake and dosage of active metabolites of vitamin D3 is determined by the initial level of the blood sugar.

In addition, in the treatment of femoral neck fractures, the appointment of calcium preparations is mandatory, since it is known that the daily requirement of calcium in patients suffering from osteoporosis should be at least $1.5 \mathrm{~g}$ per day. The unique role of calcium in providing the structure of bone 
tissue and the regulation of intracellular processes is shown in numerous experimental and clinical studies [10]. Calciumemia, being a strict constant, is normally maintained by the intake of calcium from food. With insufficient intake of calcium, or with a violation of the absorption process in the intestine, this element is mobilized from the bone tissue, which contains $99 \%$ of its total amount in the body $[19,20]$.

Prolonged preservation of the negative balance of calcium worsens the metabolism of bone tissue, exacerbating the manifestations of osteoporosis. Deficiency of dietary calcium is considered as one of the most serious risk factors for the development of primary forms of osteoporosis. The rate of daily intake of calcium, depending on age and physiological status, ranges from 1000 to $1500 \mathrm{mg}$ per day. However, in the diet of residents of developed countries is not always this amount. Thus, in the USA, where the number of patients with osteoporosis has been steadily increasing for many years, the daily intake of calcium from food is usually 500-650 mg.

Supplementation of calcium-containing products (calciumenriched cottage cheese) has a positive effect on calcium homeostasis in patients with postmenopausal and senile forms of systemic osteoporosis [21]. In the same study, it was shown that the additional intake of calcium from food in experimental animals (rats) enhances the process of bone formation. In the experimental group of animals, when compared with the control group, a significant increase in the weight of the spongy bone, a decrease in the porosity of the cortical plate and an increase in the cavities filled with the newly formed bone tissue were revealed.

According to Aloia J et al. [2], daily intake of $1700 \mathrm{mg}$ of calcium and 400 units of vitamin D3 reduces the rate of bone loss in the femoral neck in postmenopausal women.

The solution of the problem of sufficient provision of the calcium population by many researchers sees in the appointment of calcium preparations. It is proved that in this case the loss of cortical bone is reduced, which, as is known [22], plays a leading role in ensuring the strength of the neck of the femur. In observed patients with femoral neck fractures on the background of osteoporosis, in all cases with adequate osteosynthesis and pharmacological correction of the bone tissue remodeling processes, fusion was achieved in usual terms. X-ray densitometry, performed 6 months after the operation, showed that the appointment of pharmaceuticals not only prevented the loss of bone tissue in the opposite neck of the thigh, but also increased its mass (on average by $2.6 \%$ ) in more than half of cases.

Identified in $9 \%$ of cases (despite fracture fusion), the decrease in BMD on the opposite side was assessed as a consequence of an inadequate dose of drugs and confirmed the necessity of its longer appointment $[23,24]$. The need to use pharmaceuticals is visible when comparing the results with the results of repeated DXA in the control group, where the loss of bone mass in the opposite cervical region is noted in $82 \%$ of cases. In the remaining $18 \%$ of cases BMD dynamics was insignificant, but during the first year after the operation, 4 fractures of the contra lateral femoral neck occurred in the control group [25]. In 3 cases, the fracture fusion after the operation was lengthened, in one-a false joint was formed. The obtained data give us grounds to state that under the expected further increase in the number of patients with osteoporosis, the solution to the problem of fractures against its background can consist only in a complex of therapeutic measures, including along with surgical treatment (as an obligatory first stage) the use of a second stage of pharmaceuticals that affect remodeling mechanisms and able not only to increase the mass of bone, but also to improve its quality. Doses and the sequence of prescription of drugs are determined by the initial level of blood Ca [26].

\section{References}

1. Akkus O, Adar F, Schaffler MB (2004) Age-related changes in physicochemical properties of mineral crystals are related to impaired mechanical function of cortical bone. Bone 34(3): 443-453.

2. Aloia JF, Vaswani A, Yeh JK, Ross PL, Flaster E, et al. (1994) Calcium supplementation with and without hormone replacement therapy to prevent postmenopausal bone loss. Ann Intern Med 120(2): 97-103.

3. Moyer VA (2013) Vitamin D and calcium supplementation to prevent fractures. Rockville, MD: U.S. Preventive Services Task Force recommendation statement. Ann Intern Med 158(9): 691-696.

4. Crespo R, Revilla M, Crespo E, Villa L, Rico H (1997) Complementary Medical Treatment for Colles' Fracture: A Comparative, Randomized, Longitudinal Study. Calcif Tissue Int 60(6): 567-570.

5. Elders PJ, Netelenbos JC, Lips P, van Ginkel FC, Khoe E, et al. (1991) Calcium supplementation reduces vertebral bone loss in perimenopausal women a controlled trial in 248 women between 46 and 55 years of age J Clin Endocrinol Metab 73(3): 533-540.

6. World Health Organization (WHO) (1994) Study Group. Assessment of fracture risk and its application to screening for postmenopausal osteoporosis. Report No: 843, World Health Organization, Geneva, Switzerland, Europe 1-134.

7. (2000) Osteoporosis prevention, diagnosis, and therapy. NIH Consensus Statement 17: 1-45.

8. (2010) The North American Menopause Society (NAMS). Management of osteoporosis in postmenopausal women: 2010 position statement of The North American Menopause Society. Menopause 17(1): 23-24.

9. Jordan GR, Loveridge N, Bell KL, Power J, Rushton N, et al. (2000) Spatial clustering of remodeling osteons in the femoral neck cortex: a cause of weakness in hip fracture. Bone 26(3): 305-313.

10. Lim LS, Hoeksema LJ, Sherin K (2009) Screening for osteoporosis in the adult U.S. population: ACPM position statement on preventive practice. Am J Prev Med 36(4): 366-375.

11. (2010) Institute of Medicine (IOM). Dietary reference intakes for calcium and vitamin D. Washington DC: National Academy of Sciences, USA.

12. Cranney A, Weiler HA, O’Donnell S, Puil L (2008) Summary of evidencebased review on vitamin $\mathrm{D}$ efficacy and safety in relation to bone health. Am J Clin Nutr 88: 513S-519S.

13. Melton LJ (2000) Epidemiology of fractures. Riggs BL, Melton LJ (Eds), Osteoporosis: etiology, diagnosis, and management, Raven Press, New York. 
14. Nishii Y (2003) Rationale for active vitamin D and analogs in the treatment of osteoporosis. J Cell Biochem 88(2): 381-386.

15. Huusko TM, Karppi P, Kautiainen H, Suominen H, Avikainen V, et al. (2002) Randomized, double-blind, clinically controlled trial of intranasal calcitonin treatment in patients with hip fracture. Calcified Tissue International 71(6): 478-484.

16. Florence R, Allen S, Benedict L, Compo R, Jensen A, et al. (2013) Diagnosis and treatment of osteoporosis. Bloomington, MN: Institute for Clinical Systems Improvement, USA.

17. (2010) National Osteoporosis Foundation. Clinician's guide to prevention and treatment of osteoporosis. National Osteoporosis Foundation, Washington, D.C, USA, pp: 1-56.

18. Burge R, Hughes D B, Solomon DH, Wong JB, King A, et al. (2007) Incidence and economic burden of osteoporosis-related fractures in the United States, 2005-2025. J Bone Miner Res 22: 465-475.

19. Johnell O, Kanis J (2005) Epidemiology of osteoporotic fractures. Osteoporos Int 16(2): S3-S7.

20. World Health Organization WHO (2004) Scientific Group on the assessment of osteoporosis at primary health care level: Summary meeting report. Brussels, Switzerland, Europe, p: 1-17.

This work is licensed under Creative

Commons Attribution 4.0 Licens

DOI: 10.19080/OAJS.2018.07.555719
21. Shiraki M, Fukuchi M, Kiriyama T, Okamoto S, Ueno T, et al. (2004) Alfacalcidol reduces accelerated bone turnover in elderly women with osteoporosis. J Bone Miner Metab 22(4): 352-359.

22. U.S. Preventive Services Task Force (2011) Screening for osteoporosis: U.S. preventive services task force recommendation statement. Ann Intern Med 154(5): 356-364.

23. Gourlay ML, Fine JP, Preisser JS (2012) Study of Osteoporotic Fractures Research Group. Bone-density testing interval and transition to osteoporosis in older women. N Engl J Med 366: 225-233.

24. Heany R, Dowell S, Bierman I, Hale C, Bendich A (2001) Absorbability and cost effectiveness in calcium supplementation J. Am. Coll. of Nutr 20(3): 239-246.

25. Moyer VA (2013) Vitamin D and calcium supplementation to prevent fractures in adults: U.S. Preventive Services Task Force recommendation statement. Ann Intern Med 158(9): 691-696.

26. Jackson RD, LaCroix AZ, Margery Gass, Wallace RB, John Robbins, et al. (2006) Calcium plus vitamin D supplementation and the risk of fractures. N Engl J Med 354: 669-683.

\section{Your next submission with Juniper Publishers} will reach you the below assets

- Quality Editorial service

- Swift Peer Review

- Reprints availability

- E-prints Service

- Manuscript Podcast for convenient understanding

- Global attainment for your research

- Manuscript accessibility in different formats

( Pdf, E-pub, Full Text, Audio)

- Unceasing customer service

Track the below URL for one-step submission https://juniperpublishers.com/online-submission.php 